http://jmscr.igmpublication.org/home/ ISSN (e)-2347-176x ISSN (p) 2455-0450 crossref DOI: https://dx.doi.org/10.18535/jmscr/v8i7.85

\title{
Extra- Gastrointestinal Stromal Tumor (EGIST)
}

\author{
Authors \\ Dr Shabnum Thakur (MD Radiotherapy) ${ }^{1}$, Dr Kapil Mohan Pal (MD Radiotherapy) ${ }^{2 *}$, \\ Dr Anup Negi (MD Radiotherapy) ${ }^{3}$, Dr Lalit Chandrakant ${ }^{4}$, Dr Manish Gupta ${ }^{5}$ \\ ${ }^{1,2,3,4}$ Senior Resident, Department of Radiotherapy \& Oncology, IGMC Shimla (H.P), India \\ ${ }^{5}$ Professor, Department of Radiotherapy \& Oncology, IGMC Shimla (H.P), India \\ *Corresponding Author \\ Dr Kapil Mohan Pal (MD Radiotherapy)
}

Senior Resident, Department of Radiotherapy \& Oncology, IGMC Shimla (H.P), India

\begin{abstract}
Majority of mesenchymal neoplasms of gastrointestinal tract are gastrointestinal stromal tumors (GISTs). EGISTs, are the neoplasms which overlaps their histologicaland immunohistological features with those of GISTs, and are found in the abdomen outside of the gastrointestinal tract with no connection to the gastric or intestinal wall. A case of EGIST is reported to show a rare differential diagnosis of an abdominal tumor (arising in abdomen adherent with uterus and appendix in a 66 years old women), emphasizing the proper treatment due to correct diagnosis.

Keywords: Extra gastrointestinal stromal tumors (EGIST), mesenchymal, imatinib.
\end{abstract}

\section{Introduction}

Extra gastrointestinal stromal tumors (EGIST) are rare mesenchymal tumor lesions located outside the gastrointestinal tract.Gastrointestinal stromal tumors (GIST) are the most common mesenchymal neoplasm of GI tract ${ }^{1}$. GIST can occur in any part of GI- tract. The location outside the GI tract can occur in $10 \%$ of the cases, and, in such case, they are called EGIST ${ }^{2}$. According to a systematic review, the incidence of GIST is ascertained to be 10-15/million/years without significant geographical variation ${ }^{3}$. The most common age group in which higher incidence is seen is 60-65 years and rarely before 40 years and only $<1 \%$ below 21 years. The diagnosis can be made through CT-guided puncture and immunohisto-chemical (IHC) analysis of the biopsy. There are three histological types: spindle (70\%), epithelial (20\%), and mixed-cell. In 95\%, there is somatic mutation of CD117 (c-kit), and its discovery in the IHC characteristically defines the GIST $^{4}$. Staging could be done with abdominal and pelvis tomography, MRI, or PET-CT ${ }^{5}$.In the digestive tract, stomach is the most common location, followed by jejunum, ileum, duodenum and colorectum ${ }^{6}$. Rarely, they are seen at extraintestinal sites such as omentum ${ }^{7}$, mesentery $^{8}$, gall bladder ${ }^{9}$ pancreas $^{10}$ retro 
peritoneum, paravaginal tissue, periprostatic tissue, and in the pleura. Traditionally, GISTs are diagnosed based on their morphology (spindle cell, epithelioid, or mixed) and immunohistochemistry (IHC) with CD117, though it has low specificity. Over time, a more sensitive and specific marker, discovered on GIST1 (DOG1) was developed. Although considered to be the mostcommon mesenchymal tumors of the GIT, the overall incidence of GISTs is low and that of extra intestinal GISTs (EGIST) is even rarer $^{11}$.

\section{Case Report}

A 66-Year-old female patient presented to surgery department with chief complaints of pain abdomen and abdominal distension for 1 year. Pain was intermittent, dull aching in nature and got temporarily relieved by taking medication. It was associated with abdominal distension. General examination was done. Patient was afebrile with blood pressure of $128 / 70 \mathrm{~mm} \mathrm{Hg}$, Pulse of $79 / \mathrm{min}, \mathrm{RR}$ of $24 / \mathrm{min}$. Abdominal examination revealed a single, mildly tender, firm, $10 \times 8 \mathrm{~cm}$ mass in the hypogastric region, extending into the umbilical region. The mass is moving downwards with respiration, has restricted intrinsic mobility, bimanually palpable, falling forwards in knee-elbow position and the abdomen is tender. There was no palpable Organomegaly. A dull note is heard on percussion with a band of resonance in front. $\mathrm{P} / \mathrm{R}$ and other Systemic examination were normal. Haemogram revealed anaemia $(\mathrm{Hb}=7.0 \mathrm{gms} \%)$ and a normal peripheral smear study. Liver function tests and renal function tests and electrolyte panel were within normal limits. Chest radiograph showed no abnormalities.(CECT) Contrast enhanced computed tomography was done which was suggestive of an abdominal mass which was extraintestinal of size $10 \times 10 \mathrm{~cm}$ adhered to gut and uterus (figure1). The trucut biopsy was performed which was suggestive of spindle cell neoplasm as shown in (figure 2). Patient was then taken up forexploratory laparotomy proceeds adhesion- lysis with total abdominal hysterectomy with appendectomy with resection of jejunum with bilateral salpingo-oophorectomy with omental biopsy. On opening abdomen, there was an evidence of mass of size $10 \mathrm{X} 10 \mathrm{~cm}$ which was adherent to fundus and anterior wall of uterus. Gut with mesentery wall also adherent to mass of $16 \mathrm{~cm}$ of jejunum with its mesentery infiltrating with mass. On cut section, there is evidence of degeneration hemorrhage and adhesion of appendix with mass and it was also infiltrating into myometrium. Bilateral fallopian tube and ovary were grossly normal. Macroscopic pathological evaluation of myometrium showed tumor adherent to the serosal surface and focally infiltrating into the outer half of the myometrium from serosal aspect. Senile changes were also seen. Section from intestine revealed normal intestinal wall with lumen adherent to the serosal surface. Site of adhesion showed hemorrhage, hyalinization and inflammatory cell infiltrating into the muscularis propria and serosa. Appendix showed feature of appendicitis. Microscopic evaluation showed admixture of epithelial and spindle cells. Tumor cells were arranged in short fascicles with focal satori form pattern arranged around delicate vasculature. Cells are short fusiform in shape having oval to plump spindle vesicular minimally pleomorphic nuclei and eosinophilic cytoplasm. Tumor cells with epithelioid appearance having round to oval bland nuclei with eosinophilic cytoplasmic vacuoles leading to signet ring appearance. Dilated, congested and focally thrombosed vascular spaces with foci of hyalinization, foci of hypercellularity, areas of increased mitosis (more than 25 in 50 high power fields) along with foci of ischemic necrosis and hemorrhage. Immunohistochemically epithelioid areas were ckit (CD 117) and DOG1 positive as shown in (figure 3 and 4). The KI 67 proliferative index was 50\%. Keeping in view macroscopic and microscopic histopathological findings and the IHC analysis, diagnosis of extra intestinal, gastrointestinal stromal tumor (extra GIST) was 
made. The patient had no complications during the post op period and had normal hematological and biochemistry profile. She was started on adjuvant treatment with tablet imatinib 400mg per day and was kept on monthly visit to hospital. Patient took treatment for 3 years and was doing well till last follow up.

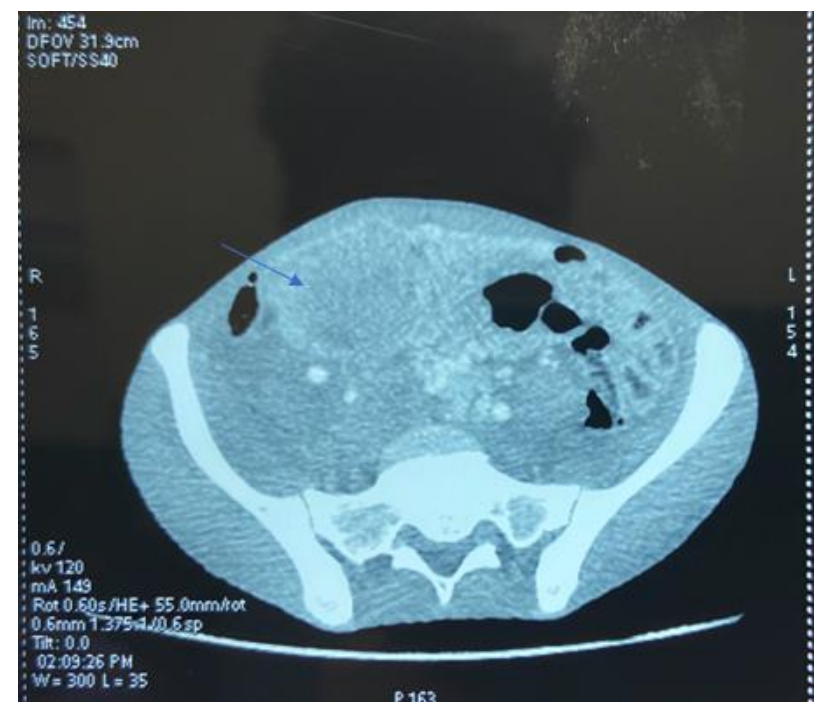

Figure 1: axial section of CECT pelvis showing heterogeneous mass

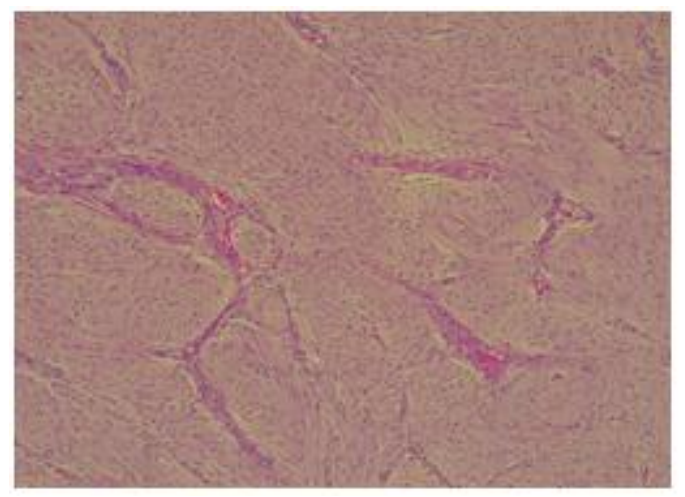

Figure 2: HPE suggestive of spindle cell neoplasm

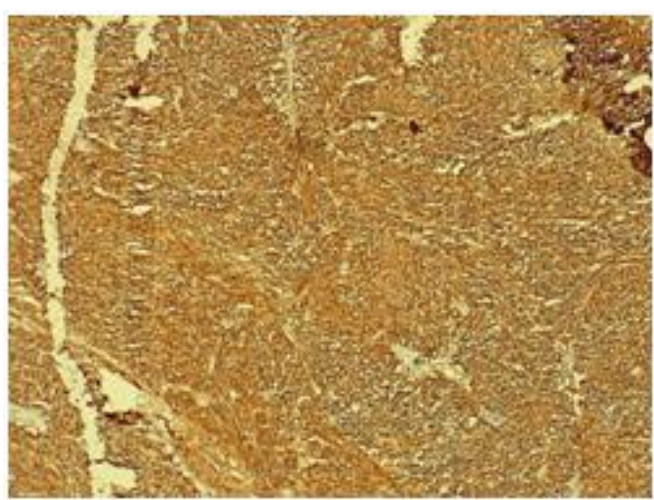

Figure 3: IHC showing positivity for DOG-1

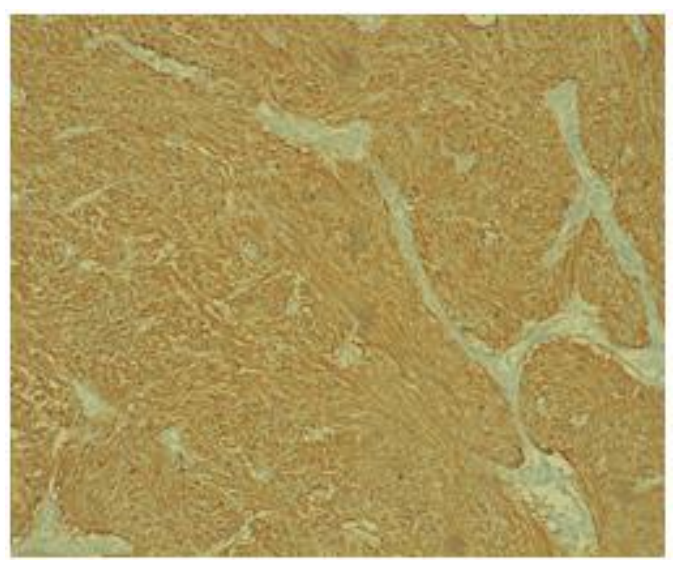

Figure 4: IHC showing positivity for CD117

\section{Discussion}

The EGIST is a rare diagnosis regarding mesenchymal tumors and can found in other sites of digestive tract like: omentum, pancreas, rectum, and small intestine. It is an important differential diagnosis of masses in the abdomen: leiomyoma, leiomyosarcoma, lipoma, schwannoma, carcinoids, and fibroids. CT/ ultrasound -guided FNAC/ trucut biopsy may provide biopsy material. The IHC analysis with CD117 (C-Kit) confirms the diagnosis ${ }^{12,13}$. A recent study showed positive immunohistochemistry in $93.3 \%$ for CD117, 70\% for CD34, and 10\% for S1007. The biopsy result in this case report was positive for CD117, DOG-1. After establishing the diagnosis, it is important to stage the tumor for better management ${ }^{14}$. The NCCN guidelines suggests that the first-line systemic treatment for advanced GIST cases is neoadjuvant therapy with Imatinib ${ }^{5}$. About $83-89 \%$ of patients responds to the treatment but may or having the progression of the disease stabilized. In nutshell, EGIST should be kept as an important diagnosis of tumor masses, especially when symptomatic, such as masses in abdomen. The correct diagnosis is very important, for delivering of best treatment.

Financial Assistance: None Conflict of Interest: Nil

\section{References}

1. Alkhatib L, Albtoush O, Bataineh N, Gharaibeh K, Matalka I, Tokuda Y. Extra 
gastrointestinal stromal tumor (EGIST) in the abdominal wall: Case report and literature review. Int J Surg Case Rep 2011;2:253- 5 .

2. J. H. Yi, B.-B. Park, J. H. Kang et al., "Retrospective analysis of extragastrointestinal stromal tumors," World Journal of Gastroenterology, vol. 21, no. 6, pp. 1845-1850, 2005.

3. Søreide K, Sandvik OM, Søreide JA, Giljaca V, Jureckova A, Bulusu VR. Global epidemiology of gastrointestinal stromal tumours (GIST): A systematic review of population- based cohort studies. Cancer Epidemiol2016;40:39- 46.

4. D. M. Dorfman, M. M. Bui, R. R. Tubbs et al., "The CD117 immunohistochemistry tissue microarray survey for quality assurance and inter laboratory comparison a College of Amer- ican Pathologists Cell Markers Committee Study," Archives of pathology \& laboratory medicine, vol. 130, no. 6, pp. 779-782, 2006.

5. National Comprehensive Cancer Network, "Soft tissue sarcoma, version 2.2016, NCCN clinical practice guidelines in oncology,"

http://www.jnccn.org/content/14/6/758.full.

6. Liegl- Atzwanger B, Fletcher JA, Fletcher CD. Gastrointestinal stromal tumors. Virchows Arch 2010;456:111- 27.

7. Murayama Y, Yamamoto M, Iwasaki R, Miyazaki T, Saji Y, Doi Y, et al. Greater omentum gastrointestinal stromal tumor with PDGFRA- mutation and hemoperitoneum. World J Gastrointest Oncol 2012;4:119- 24.

8. Kirby R, Rajasagaram N, Ghusn $\mathrm{M}$. Primary mesenteric gastrointestinal stromal tumour. J Surg Case Rep 2014;2014. pii: Rju050.
9. Peerlinck ID, Irvin TT, Sarsfield PT, Harington JM. GIST (gastro- intestinal stromal tumour) of the gallbladder: A case report. ActaChirBelg2004;104:107- 9.

10. Trabelsi A, Yacoub- Abid LB, Mtimet A, Abdelkrim SB, Hammedi F, Ali AB, et al. Gastrointestinal stromal tumor of the pancreas: A case report and review of the literature. N Am J Med Sci2009;1:324- 6.

11. Casella C, Villanacci V, D'Adda F, Codazzi M, Salerni B. Primary extra- gastrointestinal stromal tumor of retroperitoneum. Clin Med Insights Oncol 2012;6:189- 97.

12. M. Miettinen, W. El-Rifai, L.Sobin, and J. Lasota, "Evaluationof malignancy and prognosis of gastrointestinal stromal tumors: a review," Human Pathology, vol. 33, no. 5, pp. 478-483, 2002.

13. Y. Shinomura, K. Kinoshita, S. Tsutsui, and S. Hirota, "Patho- physiology, diagnosis, and treatment of gastrointestinal stromal tumors," Journal of Gastroenterology, vol. 40, no. 8, pp. 775780, 2005.

14. N. Quezada, F. Acevedo, A. Marambio et al., "Complete patho- logical response to Imatinibmesylate in an extraintestinal gastrointestinal stromal tumor," International Journal of Surgery Case Reports, vol. 5, no. 10, pp. 681-685, 2014. 